UNIVERSITÀ

CATTOLICA

del Sacro Cuore

DIPARTIMENTO DI POLITICA ECONOMICA

The present, past, and future

of labor-saving technologies

Jacopo Staccioli

Maria Enrica Virgillito

Quaderno n. 13/dicembre 2020 
Università Cattolica del Sacro Cuore

DIPARTIMENTO DI POLITICA ECONOMICA

\title{
The present, past, and future of labor-saving technologies
}

\author{
Jacopo Staccioli \\ Maria Enrica Virgillito
}

Quaderno n. 13/dicembre 2020

\section{VP VITA E PENSIERO}


Jacopo Staccioli, Department of Economic Policy, Università Cattolica del Sacro Cuore, Milano - Institute of Economics, Scuola Superiore Sant'Anna, Pisa

$\bowtie$ jacopo.staccioli@unicatt.it

Maria Enrica Virgillito, Institute of Economics, Scuola Superiore Sant'Anna, Pisa-Department of Economic Policy, Università Cattolica del Sacro Cuore, Milano

$\triangle$ mariaenrica.virgillito@santannapisa.it

Dipartimento di Politica Economica

Università Cattolica del Sacro Cuore - Largo A. Gemelli 1 - 20123 Milano

Tel. 02-7234.2921

$\triangle$ dip.politicaeconomica@unicatt.it

https://dipartimenti.unicatt.it/politica economica

(C) 2020 Vita e Pensiero - Largo Gemelli 1 - 20123 Milano

$\underline{\text { www.vitaepensiero.it }}$

ISBN digital edition (PDF): 978-88-343-4479-8

This E-book is protected by copyright and may not be copied, reproduced, transferred, distributed, rented, licensed or transmitted in public, or used in any other way except as it has been authorized by the publisher, the terms and conditions to which it was purchased, or as expressly required by applicable law. Any unauthorized use or distribution of this text as well as the alteration of electronic rights management information is a violation of the rights of the publisher and of the author and will be sanctioned according to the provisions of Law 633/1941 and subsequent amendments. 


\begin{abstract}
The present chapter provides a historical reappraisal of labor-saving technologies. It reviews and systematizes theoretical contributions and empirical findings documenting the presence of labor- and time-saving heuristics in innovative efforts back since the First Industrial Revolution. More in detail, with the help of various patent analyses, the chapter documents the presence of labor-saving heuristics in the latest wave of technological innovation, detecting the human functions substituted by the underlying technologies. Against a reductionist approach conceiving robots as the only threat for labor displacement, it shall be argued that labor-saving technologies consist of a complex and heterogeneous bundle of innovations uncovering a much wider set of artifacts and functions. Motivated by the recurrent debate on the threats of automation occurring in the last couple of centuries, evidence is provided on the existence of long waves and clusters in relevant innovations, discussing how the overall cluster of labor-saving technologies consists of heterogeneous and often independent innovations following remarkably different time-trajectories. The chapter closes with an outline of potential future trends in labor-saving technologies and room for policy actions.
\end{abstract}

JEL classification: O3, C38, J24.

Keywords: Human-Machine Relationship, History of Technology, Labor-Saving Heuristics. 


\section{Introduction}

Fear of technological unemployment is a recurrent phenomenon which has characterized various phases in the history of capitalism. Classical economists, such as David Ricardo and Karl Marx, had clear the potential labor displacement threat deriving from the use of mechanized machines. Indeed, the Luddites movement comes to mind, with British manual workers destroying machines, such as the spinning jenny, at the beginning of the 19th century (Nuvolari, 2002): these machines were recognized to have the ability of incorporating workers' knowledge, increasing productivity, and therefore being a potential driver of labor expulsion.

Eventually, the image of Luddites turned out into the one of the Taylorist shop-floor, with time-and-motion studies applied to the assembly line, and popularized by Charlie Chaplin one century later. With massproduction coexisting with growing consumer demand, deskilling and alienation, rather than outright labor expulsion, became the primary workers' concerns. Later on, car manufacturing and, in general, manufacturing of "white" goods, turned into the symbol of the Fordist phase, wherein workers could afford to buy what they produced. However, during that very phase, an important report on the impact of automation on labor demand was commissioned by the U.S. government (National Commission on Technology, Automation, and Economic Progress, 1966).

With the advent of microchips, with the increasing importance of immaterial goods, and with the subsequent wave of globalization, open-space offices, equipped with computers with black screens processing green and white symbols, became the new icon of human-machine relationship. No more scientific management applied to assembly lines, but rather white-collar workers and their own computers. As with the ICT revolution computers were becoming the dominant technological design in workplaces, in 1980s alarm bells about technology substituting humans started ringing again (Freeman et al., 1982).

Back to the present, technology has never been so widespread among humankind, in various and differentiated forms, hugely investing both the production and reproduction spheres. Internet takes the place of electricity, social media of television, and virtual life appears as important as the real one. Given the purported benefits to societies from the use of technology, a new wave of fear of technological unemployment would seem misplaced. Nonetheless, the topic has received fresh attention in recent times.

Concerns are motivated by the emergence of artifacts embedding some forms of "intelligent automation". Among these, "intelligent robots" are of particular interest to academic and public discourses. Once emotionless machines, in recent years these artifacts have been equipped with learning algorithms able to process enormous amount of data in real-time and perform functions like classification and interaction with humans. Since 2014 and after the Great Recession, a new literature has flourished, providing figures and forecasts about the future of work. The ground is clearly contested between techno-optimists and techno-pessimists, both in general sharing a strong deterministic perspective on the unfolding of technologies within sectors of activities, firms, and their impact upon labor.

However, a full understanding of the technological complexity underlying robotics and automation is still lacking. Indeed, robots are convoluted artifacts whose use may be either labor-augmenting or labor-displacing. Moreover, there is lack of awareness of the actual direction taken by innovative efforts and search heuristics targeting labor-saving activities. An investigation of search heuristics within labor-saving production techniques allows a genuine understanding of which exact human functions technologies are expected to replace.

In this chapter, the current debate on human-machine relationship is reviewed, giving space also to critical perspectives on the dominant approach put forth by traditional labor economics. Then, incumbent literature is discussed, focusing on search heuristics within labor-saving technologies and on their historical roots. Finally, future possible trends regarding human-machine relationship are envisioned. 


\section{Human-machine relationship in the current debate}

The massive introduction of robotized work certainly characterizes the manufacturing sector, with robotic devices able to substitute for repetitive and "routinized" activities. Investment in automation, however, reached a saturation level, particularly along assembly lines, already in 1990s (Krzywdzinski, 2020). More recently, artificial intelligence and other computational breakthroughs have become increasingly relevant also to the service sector, which nowadays employs the largest share of workforce. As a direct consequence, robotization and artificial intelligence represent a threat not only to blue-collar workers, but for white-collars as well. While the ability of the Deep Blue supercomputer to defeat chess grandmaster Garry Kasparov in 1997 did not come as a great surprise, the challenge undertaken by IBM in 2004 to develop a question-answering machine, Watson, to beat human champions in Jeopardy!, is more eye-opening. Unlike chess, Jeopardy! is an open domain game which requires pronounced learning, linguistic, semantic, and association skills. These cognitive abilities are not usual characteristics of computers at all. The victory of Watson in 2011 over champions Brad Rutter and Ken Jennings confirms the possibility that machines are not only able to compute, but, to a certain extent, also to understand, learn, and react to mutable environments and information. In other words, machines seem to be on the way of becoming "intelligent". Algorithms are nowadays able to compose music, paint artworks, write newspaper articles, and engage in other previously unthinkable activities. All in all, not only low cognitive abilities, but also higher ones may be potentially replaced by technology.

Is this a good news? In fact, many emerging companies in the Silicon Valley or other high-tech districts are explicitly devoted to creating and developing technologies able to entirely substitute human labor. For instance, Momentum Machines Co., incorporated in 2013, has the goal of completely automatizing production of gourmet hamburgers. Its founders explicitly state how their device is not simply meant to increase labor efficiency, but rather to get rid of human labor force (Ford, 2015).

Conversely, sectors like medicine and healthcare are still at an early adoption stage of robots and machine learning algorithms, whose massive usage could be complementary to human activity, rather than replacing it. Potentially, there is ample room to go well beyond the use of robots and artificial intelligence in already standardized and highly productive sectors, like fast-food preparation and delivery, to less standardized sectors, like medicine and healthcare, whose cost curves are disproportionately steep, threatening healthcare access by a soaring fraction of the population, both in countries which have universal coverage (e.g. most European countries) and those which do not (e.g. the U.S.).

Does all this constitute a "Fourth Industrial Revolution", or is it rather part of some incremental deepening and convergence of pre-existing technological paradigms? The question is very important as it stands at the core of the analysis of continuities and discontinuities of knowledge bases, of firms and institutions generating and supporting them, and of the nationality of leading actors. It is crucial distinguishing between so-called "Industry 4.0" (I4.0) managerial and policy strategies on the one hand, and the evidence which might support the arrival of a breakthrough technological revolution, on the other (Dosi and Virgillito, 2019).

\subsection{Tasks vs. humans in productive activities}

The dominant framework for the explanation of humane-machine relationship relies on the so-called task-based approach. Popularized by Autor et al. (2003), it considers the bundle of tasks executed by each worker as the most-important dimension upon which technological change and, particularly in earlier versions, the use of computer at work, shapes the dynamics of occupations. Notably, the routine vs. non-routine dichotomy has become mainstream in economic literature. The underlying idea is that some human tasks can be more easily substituted by technological change, represented by the use of computers, while others are less so. The degree 
of substitutability depends on the amount of codified knowledge required to execute a given task. In Autor et al. (2003), which leverages on the U.S. DOT dictionary of occupations, tasks considered to be substitutable by technological change include "setting limits, tolerances, or standards", and "finger dexterity", while complementary tasks include knowledge of mathematics, "direction, control, planning", and "eye hand foot coordination". The first two activities are called "routine cognitive" and "routine manual", while the remaining three are "non-routine analytical", "non-routine interactive", and "non-routine manual" respectively. It is noteworthy that the task-based approach is rooted on the previous conceived skill-biased technical change (SBTC) approach.

A few years later, Acemoglu and Autor (2011) proclaim on the Handbook of Labor Economics the defeat of SBTC theory, defined thereby as the "canonical" model. The latter was developed during 1990s mainly by Katz and Murphy (1992) to account for U.S. wage inequality, explained via different premia on behalf of low- and college-educated workers. According to Acemoglu and Autor (2011), although this framework has the merit of explicitly encompassing the skill-biased nature of technical change, explaining the college/high-school earning gap, it has the shortcoming of predicting an increase in economy-wide average wage and real wage of each skill group, unless supply becomes more abundant, as a result of factor augmenting technical change. In this respect, the canonical supply-demand model is not able to account for a declining earnings, in absolute term, of low skilled workers, because of the absence of a comparative advantage mechanism, and to account for the different behavior of the earning distribution across quantiles, the so-called "polarization". Additionally, by focusing only on two skill types, SBTC is unable to account for declining labor demand in so-called "middle" occupations. Third, being based on skills rather than tasks, SBTC cannot aptly account for true human-machine interaction: while skills are a worker's attribute, tasks depends on the technology in use. Finally, by predicting the ultimate effect of technology as productivity-enhancing via a factor-augmenting form, substitution effects are entirely neglected. Aimed at overcoming these limitations, the routine-biased technical change (RBTC) theory becomes the dominant framework, distinguishing three types of task, high-, medium-, and low-skill, and the comparative advantage of workers belonging to each category, allowing for substitutability of those facing a comparative disadvantage because of task-biased technology, and of their respective earning. Empirically, it generally adopts, as proxy of technical change, the sectoral share of workers equipped by computer, and as tasks' measure, versions of the dictionary of occupations or alternatively of O*NET for the U.S., PIAAC for OECD countries, EWCS for Europe, BIBB/IAB for Germany (Biagi and Sebastian, 2020).

From computers to robots, automation regains attention after the Great Recession, also popularized by contributions like Brynjolfsson and McAfee (2014) and Ford (2015), which anticipate that machines will win the race against humans and put forward dystopian scenarios of human-free workplaces. As a result, a number of recent studies rely on a new variable to account for technical change, namely the sectoral share of robots per number of employees. Indeed, the RBTC framework, previously used to account for digitalization, is reoriented towards the analysis of automation. In this respect, distinctions between computer-human vs. machine-human relationships are never truly investigated.

Acemoglu and Restrepo $(2018,2019,2020)$ are among the contributions relying on the share of robots per employee as a proxy of technological change, and refining the model in Acemoglu and Autor (2011) in order to account for two separate effects of automation: a so-called reinstatement effect, according to which new tasks are created by automation technologies to be executed by humans, and a substitution effect, where tasks previously attributed to labor move to capital. These industry-level studies, based on local labor markets analyses, generally predict that a higher number of robots per employee decreases wages and occupations for low-wage workers. Nonetheless, a cross-country study at the industry level does find positive impact of robotic adoption on labor productivity, and less clear-cut evidence on employment reduction (Graetz and Michaels, 
2018). Labor-shedding effects are found for low-skilled rather than medium-skilled workers. However, studies adopting firm-level data provide a different picture: in general, robotic adoption, or alternatively, imported capital equipment, are not found to produce labor expulsion, but rather employment growth (Domini et al., 2020; Koch et al., 2019). On the contrary, disproportionate figures on employment losses are reported by Frey and Osborne (2017), relying on the Delphi method in defining technological bottlenecks and on the RBTC approach, subsequently downward reviewed by Arntz et al. (2016).

\subsection{Beyond RBTC theory}

The recent findings on robots/automation adoption against employment patterns mimic a long research tradition in the economics of innovation which, starting with the seminal work by Chris Freeman and associates in 1980s (Clark et al., 1981; Freeman and Soete, 1987), distinguishes between alternative effects of technical change on employment, theoretically discussing different compensation mechanisms balancing labor-saving effects of innovation (Piva and Vivarelli, 2018; Simonetti et al., 2000; Vivarelli, 1995). In general, survey-based studies conducted on the pre-robots era seem to confirm that sectoral analyses on the impact of process innovation, indeed including robotics and automation, highlight a negative employment impact. On the contrary, firm-level studies are found to report positive effects of process innovation (Calvino and Virgillito, 2018). The firm-sector ambiguity derives from the undergoing competitive and selection processes occurring in the market. A firm gaining market share, e.g. because of investments in robotic, automation, and in general of process innovation, might well increase its labor demand because of higher sales. However, the underlying sector might witness an overall decrease in employment growth if the firm is able to increase its market share at the expense of existing competitors (Dosi and Mohnen, 2019).

The underlying element, relied upon by both RBTC and the task-based approach, is the existence of a given degree of substitutability between labor and capital along isoquants. The relative cost of labor vs. capital ultimately defines the direction of technical change, whether labor-saving or labor-augmenting. However, the existence of inputs substitutability is anything but a resolved issue in economics. An alternative perspective comes from the evolutionary theory of technical change and the capability-based theory of the firm. According to these approaches, first, the degree of substitutability between human and machines is fixed along a given technological trajectory. Therefore, eventual labor displacing or augmenting effects of technology have to be understood not just along a given technique of production, but rather in light of the introduction of a new technique which requires less labor vis-à-vis capital. Second, technology has to be understood as an ensemble of recipes, consisting of both codified and non-codified knowledge. What regulates the space of human intervention on the production process is not simply the pace of technological change, but rather organizational routines, namely the ensemble of iffthen conditions occurring among the members of a given organization (Dosi and Nelson, 2010). The routine/non-routine dichotomy poorly explains which tasks are ex-ante expected to be substituted and which to be augmented by technologies, once organizational practices are taken into account. For instance, the so-called "Toyota-way" of production has always kept a low degree of automation inside Toyota manufacturing plants, independently of occurring innovative waves. Third, according to the Schumpeterian distinction between product and process innovation, nowadays rephrased as reinstatement vs. displacement, what innovation creates or destroys is not tasks, but rather products or sectors of activity (Freeman and Soete, 1987) at the macro level, and divisions and units at the firm-level, because of internal product-diversification and economies of scale (DuPont Chandler Jr., 1993). After all, labor demand is not divisible by tasks. Fourth, the very nature of technical change, whether embodied or disembodied, impacts upon the underlying relationship with employment (Dosi et al., 2019). Fifth, activities such as planning, machines set up, process and equipment control are hardly routinized and require precision, distributed attention, and selective knowledge 
(Pfeiffer, 2018). Empirical evidence in favor of the coexistence of cognitive and manual dexterity in manufacturing process are reported in Cetrulo et al. (2019) which, well beyond the routine/non-routine dichotomy, identify internal hierarchies and power attributes as the most relevant dimension to define what people do at work.

From sectors to firms, based on an anti-deterministic perspective on technology and stressing the role of the combination of technological and organizational changes as drivers of transformation in terms of humanmachine relationship, Cirillo et al. (2020) hardly detect any sign of emergence of revolutionary change inside automotive factories adopting I4.0 technologies. In general, organizational changes accompanied with the adoption of I4.0 technologies find a pattern of continuity with the lean production paradigm, and the I4.0 strategy, fostering 'leanness' in the production system, hardly represents a paradigm shift. In fact, the 'new' I4.0 tension towards customization, reduction of inventories, elimination of bottlenecks, tracking of errors, intensification and saturation of working time, and in general of process and organizational innovation, overlaps remarkably with the first wave of lean production begun in late 1970s. A similar reasoning is put forward by Cetrulo and Nuvolari (2019) and Pardi et al. (2020), who consider the current I4.0 wave more as a hype than a revolution, fostered by national industrial policies aimed at bolstering digital manufacturing. More importantly, rather than towards automation, I4.0 seems to be oriented towards digitalization and interconnection. Indeed, what Cirillo et al. (2020) emphasize is that more complex processes in terms of task-standardization rather than task-substitution are ongoing in the manufacturing sector. In favor of reducing anxiety versus automation, Krzywdzinski (2020) argues that the number of robots per worker is not a very telling figure of the degree of technological change in place in automotive factories, which are instead more directed towards the achievement of digitalization. For example, assembly line robots declined, as a fraction of overall industrial robots in Germany between 1993 and 2015, while their stock remained fairly constant during the same period. Notably, studies based on field-work analyses are in general able to detect heterogeneous impacts of automation at the department level. Therefore, while welding, machining, and material handling were already highly automatized in 1990s, labor disappeared neither from assembly lines, nor from quality control and testing units. In this respect, the human-based component inside factories still remains predominant. Additionally, by looking at the share of production (blue-collar) workers over total employment in the automotive industry, the author finds that country heterogeneity is rather strong (comparing Germany, Japan, and U.S.) and that the trend is not uniquely declining.

\subsection{Technologies in social reproduction}

A fresh hint of a possible paradigmatic change concerns the pervasiveness of collection and use of data to achieve control over the social reproduction spheres of individuals. In 2014, the State Council of China released a document launching a new pilot project, the Social Credit System. The project, whose name simply recalls some form of welfare state intervention, actually represents the first Government-endorsed program wherein "Big Data meets Big Brother", intended to rank individual citizens with respect to their degree of social conformity (Wired, 2017). By means of a massive collection of individual data, mapping the entire social spheres of people, the program intends to condition the possibility of, for instance, getting the desired job, choosing the school for one's own children, and enjoying freedom of traveling abroad, on the individual degree of trustworthiness. For obvious reasons, the ranking algorithm is closed source and proprietary, although five factors are known to be at play: being a good tax-payer, a good borrower (in the sense of meeting deadlines), personal and interpersonal characteristics, and preferences and behavior. The system provides both rewards (such as free loans) and punishments (such as restricting mobility) and is managed by a credit service company related 
to Alibaba Group Holding Limited. Clearly, the possibility, leveraged by big-data collection and analytics, of regulating the entire social sphere of individuals represents the most extreme form of digital control.

On the other side of the world, this possibility is currently massively adopted by high-tech companies. Recently, Zuboff (2015) introduced the notion of a new regime of capital organization, called "surveillance capitalism". In this respect, the Chinese "Big Brother" takes the form of the American "Big Other": at the core of this new accumulation regime lies the process of data generation/extraction, analysis, and sale. The first layer is largely a human-intense activity which ranges from consumer unintended data generation, whenever transactions on individual consumption patterns occur, up to piece-work activity based on click farms or generically crowdwork platforms and micro-work activities (such as Amazon Mechanical Turk) (Casilli, 2017; Huws, 2014). Not only humans, but even machines, and particularly robots, when integrated by means of sensors, become data generators. Such a pattern is particularly relevant for the industrial sector. This is basically an activity of extraction, as in the majority of cases data are simply appropriated, even by means of intrusive and brute-force practices, like data storage or illegal penetration on individual privacy. In this sense, the current phase of capital accumulation appears closer to a rentier-economy than to a productive capitalist economy, wherein both producers and consumer/workers enjoy the benefits of the value creation process. The second layer consists of massive profiling of consumers/users by means of artificial intelligence, a computationally intensive process mainly relying on supervised and unsupervised machine learning techniques.

The final layer is data sale: generated profiles are bundled and sold to other companies who then attempt to manipulate individual behavior through targeted advertising. All this brings the usual capitalist tendency of creating new consumer needs to a higher, unprecedented level, delivering ads and contents directly to those consumers who are already known to exhibit the highest profit potential. The Big Other turns out to be at least as coercive as the Big Brother: in fact, power becomes so pervasive that a given set of actions is not chosen because of the fear of control, implying self-control or a sense of conformity, but is perceived as one's own personal idea, for instance regarding the best restaurant, travel destination, accommodation, political preference, etc. This occurs because the algorithm is influencing and predefining the repertoire not only of admissible actions, but also of conceivable ones.

Although the social and the productive spheres might appear unrelated, Moro et al. (2019) do find evidence of increasing potential space of control inside firms adopting I4.0 technological artifacts. With strong emphasis towards digitalization and interconnection, the underlying technological artifacts deployed, like the Manufacturing Execution System, allow to collect real-time data on bottlenecks, errors along the production process, and workers productivity. Still far from the electronic bracelet wore by some Amazon warehouse workers, monitoring spaces are dramatically fed by digitalization processes, merging together personal, bureaucratic, and social forms of control.

\section{The present mapping into the past: long waves of labor-saving innovations}

The existence of labor-saving (hereafter, LS) heuristics driving the rate and direction of technological change is a documented pattern, since the inception of the First Industrial Revolution. Reducing the time of operations, increasing the saturation of takt-times, and speeding up processes and execution of functions, are the core drivers of mechanization and automation.

In the tradition of the economics of innovation, the First Industrial Revolution had been a combination of time-saving heuristics, enabled by the mechanization process, and the division of labor inside factories, together with the emergence of innovative artifacts. The role played by time-saving heuristics in shaping the direction 
of mechanization has been emphasized by von Tunzelmann (1995) with reference to the cotton industry in the British Industrial Revolution: the massive increase in labor productivity resulted from the use of innovation and discovery, through which a spinner was able to produce in a day as much yarn as previously a full year of work without mechanization (the author refers in particular to Baines, 1835).

Freeman (2019) conceptualizes the First Industrial Revolution as a paradigmatic shift emerging from the combination of time-saving heuristics on the one hand, and a new clear demarcation between working- and life-time for the working class on the other hand, an attitude absent in pre-industrial societies (Thompson, 1963), allowing workers discipline and ensuring their participation to productive activities, e.g. by turning Monday into a working, rather than a drinking, day. As corroborating evidence, using a detailed and quite granular report, the Hand and Machine Labor Study commissioned by the Department of Labor in 1899 to detect the impact of mechanization on labor productivity, Atack et al. (2020) estimate that only one-third of the increase in labor productivity (measured as time spent in a given operation) in the late 19th century was due to 'inanimate power', while the rest unexplained component remains attributed to the division of labor.

Speeding up the production process clearly maps into the need of reducing human active participation to the process itself. Therefore, time-saving and LS heuristics have been considered by economic historians as potential focussing devices (Rosenberg, 1976) guiding the search process, however of a very particular type. In general, in the development of a new artifact, inventors face technical trade-offs and bottlenecks which have to be overridden. Search heuristics might have various natures and directions (Cohen et al., 1996), going from the "make it smaller" for microprocessors, to the "make it faster" for vehicles, even to the "make it more exclusive" for status goods (such as nowadays smartphones). Indeed, focusing devices are rather heterogeneous among inventors, and as such they locally guide the search and discovery process, defining the technological trajectory inside a given established paradigm (Dosi, 1982). This is not the case for LS heuristics which, rather than local, appear to be a generalized feature of the history of innovation and in general of capitalism.

Are these LS heuristics empirically detectable? Attempts to infer heuristics and knowledge bases appear e.g. in Castaldi et al. (2009) at the artifact level, focusing on the tank technology and the evolution of its attributes over time, but also in Martinelli (2012), who uses patent-citation networks to infer the emergence of new paradigms by changes in bottlenecks and search heuristics, therefore at the so-called knowledge level. Recently, Taalbi (2017), relying on specialistic trade journals, collected information about drivers of innovative activities supposed to be relevant by innovators, and investigates eventual distinct patterns across industry and over time.

Currently, heuristics are usually inferred from the technical engineering literature and related case-studies. However, patents and their textual content also provide a good source of information to detect codified knowledge and the ensuing search heuristics. Relatedly, the use of text mining techniques enables a comprehensive study of large scale textual dataset. By looking at the full-text content of robotic patents over the last decade, Montobbio et al. (2020) are able to isolate the ones which clearly embed a LS trait. The identification of LS patents, done by natural language processing which includes probabilistic topic modeling, leads to a clear definition of the set of technological artifacts behind LS robotic patents published by the USPTO between 2009 and 2018

After identifying patents explicitly containing LS heuristics in robotic patent applications, Montobbio et al. (2020) infer the type of human activities that the technology contained in LS patents is intended to replace, by capturing both the formal technological content of the invention using patent classification codes, and the substantial purpose of broader robotic innovations, using the vector of words which characterizes each topic. Thanks to this twofold analysis, they describe those fields and activities which are more exposed to LS innovations. LS patents appear to be concentrated in particular in the following fields: (i) Transport, Storage and 
Packaging, (ii) Diagnosis and Therapy, (iii) Transmission of Digital Information, (iv) Optical elements, (v) Chemical or Physical Laboratory Apparatus (measuring and testing in chemistry), and (vi) Moving Parts.

The authors propose a taxonomy wherein it emerges that the typical tasks on which LS research effort is focused include (i) dexterity and manipulations, as in packing, storing, conveying, and handling packages in the logistics industry; (ii) activities entailing social intelligence, such as taking care of patients and the elders; (iii), activities requiring cognitive intelligence and complex reasoning, e.g. the ability of predicting, learning, classifying, and evaluating, typical of high-level professional segments. Notably, the analysis shows that the overall bundle of technologies behind LS heuristics is not simply related to robots stricto sensu, but encompasses a wider set of technologies, functions, and operations. In this respect, rather than interpreting the new wave of LS technologies as the next GPT (Trajtenberg, 2019), in order to genuinely account for the unfolding of the latest wave of LS technologies, a "technological constellation" perspective à la Freeman would be more informative.

In a subsequent paper, Staccioli and Virgillito (2020) move ahead by delving into the past, i.e. by adopting a historical technological constellation perspective and looking at the emergence and evolution of the bundle of technologies behind current LS heuristics detected in robotic technologies. Indeed, they show that mechanization and automation are not the result of a single dominant product design, but rather of a bundle of technological artifacts, which experience patterns of co-movements, anti-comovements, explosion, and dissipation. The empirical investigation, which looks at historical patent data over the period 1790-2019 vindicates, first, the underlying technological complexity, in terms of bundles of output, behind LS technologies; second, the increasing historical relevance of those technological artifacts entailing mechanization and automation; last, the absence of a neat recurrence of periodic waves of innovations. In fact, although the emergence of long waves characterizing part of these technological artifacts is detected, these are hardly periodically recurrent.

Fig. 1 shows the time evolution of the assignment of selected Cooperative Patent Classification (CPC) codes by patent examiners within each year starting from 1836. The vertical axis measures relative frequencies, i.e. the number of times the underlying $\mathrm{CPC}$ has been assigned divided by the overall number of assigned CPC codes in the same year. The vertical axis therefore measures the relative importance of each CPC vis-à-vis the rest of technological classes.

Already at a first glance, a sizeable heterogeneity emerges in their time evolution. Indeed, different CPC codes exhibit starkly different dynamics, both in terms of shape and scale. A few codes witness an overall steeply increasing trend (A61, C12, G02, G06, H01, H04, Y10S901, Y10T436), suggesting a century-long ever growing commitment to innovative effort in the underlying fields, while the remaining display a more "stationary' or even decreasing dynamics. Exploding trends characterize technologies related to computing, processing, and testing, namely pivotal functions at the core of the third industrial revolution. A more steady tendency is instead recorded for those technologies related to codes B65 and G05, mostly characterizing innovations dealing with storage, packing, conveying, and regulating control processes. Patent intensity of these technologies seems to be rather persistent over time, in a fashion more akin to enabling technologies, processes, and methods, rather than products themselves. A decaying trend is instead visible for codes B23, B25, and B62, mainly characterizing the first and second industrial revolutions, such as innovation in the agricultural sectors (land vehicles) and related to the mechanization process along assembly lines, providing hand tools, manipulators, and metal-working.

Mapping the present into the past by looking at the long run evolution of CPC codes characterizing current LS technologies, Staccioli and Virgillito (2020) provide evidence that robots are the result of a bundle of complex technological functions and artifacts which have been punctuated by different upswing and downswing phases 

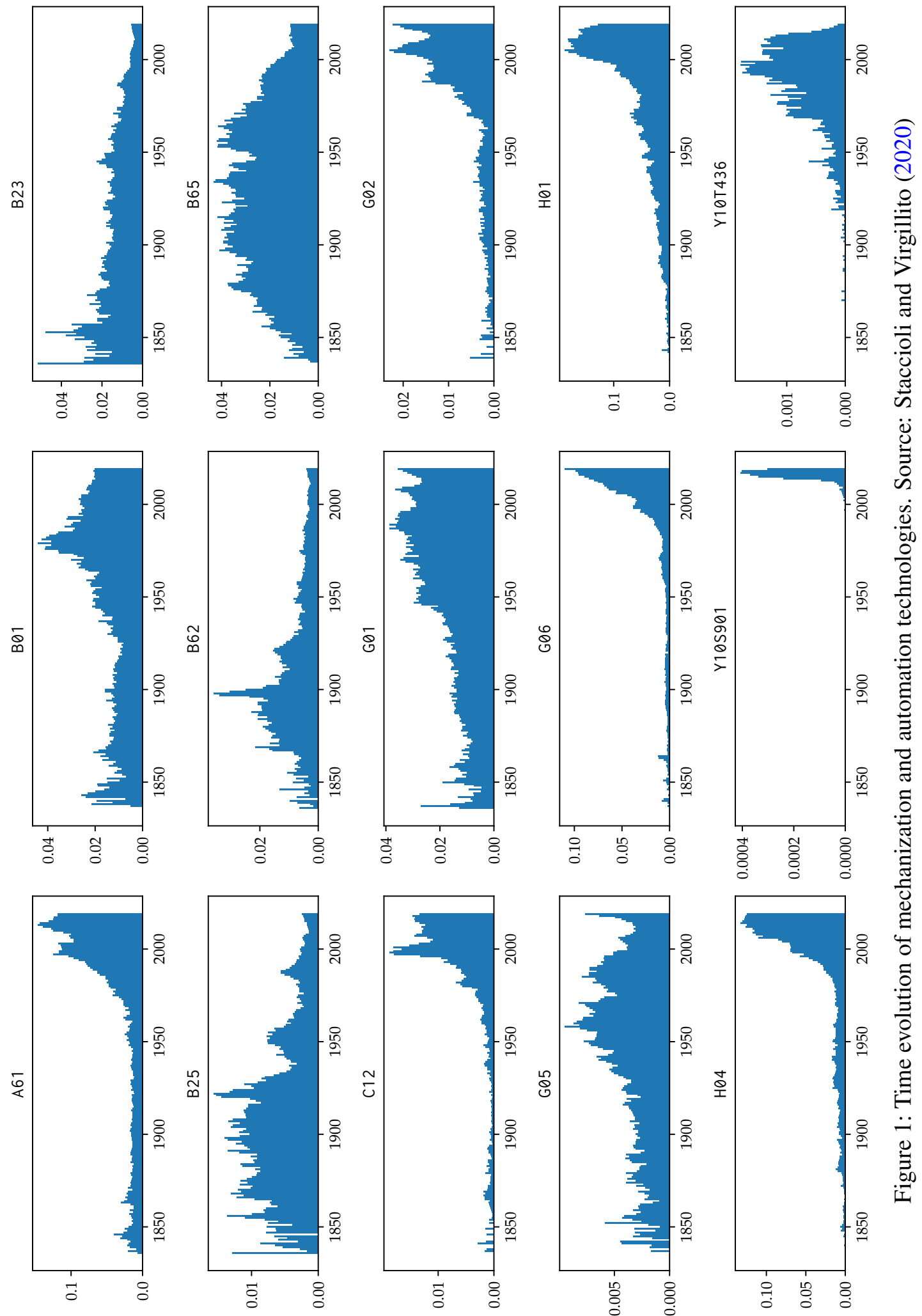


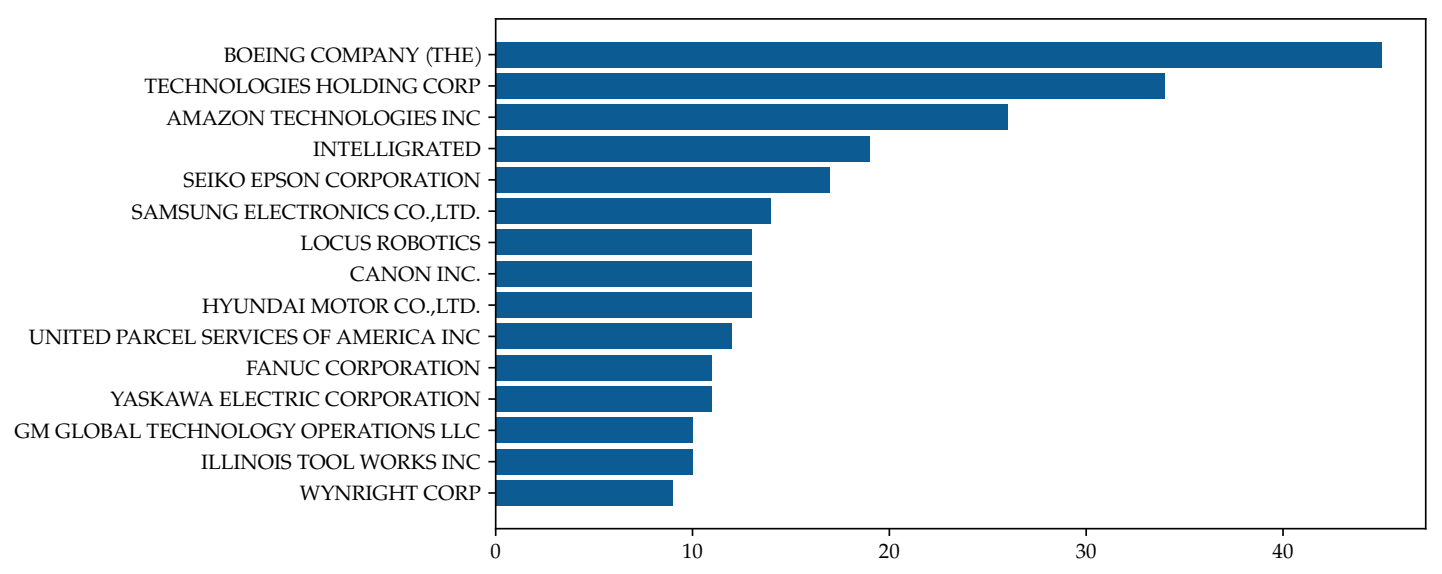

Figure 2: Top 15 labor-saving patents holders. Source: Montobbio et al. (2020).

over the last two centuries. More importantly, robots are not a unique general purpose technology but rather a cluster of heterogeneous innovations whose unfolding and diffusion is far from deterministic.

\section{The present mapping into the future}

The probabilistic topic model estimated by Montobbio et al. (2020) allows to pinpoint the technological bottlenecks underlying the search efforts on behalf of robotics inventors. Indeed, labor-saving heuristics are concentrated in human activities already identified by other contributions in the literature. Arntz et al. (2016), Frey and Osborne (2017) and Nedelkoska and Quintini (2018) all rely on experts' judgment (Delphi method) for constructing an automation probability measure of $\mathrm{O}$ NET occupations. For instance, Frey and Osborne (2017) ask technologists to reply to the following question for 70 selected occupations: "Can the tasks of this job be sufficiently specified, conditional on the availability of big data, to be performed by state of the art computer-controlled equipment?" (see Frey and Osborne, 2017, Table 1). They claim that the probability of an occupation being automated is a function of: (i) social intelligence, such as the ability to negotiate complex social relationships, including caring for others or evaluate differences; (ii) cognitive intelligence, such as the ability of solving complex problems; (iii) finger dexterity and manipulation, such as the ability to carry out precise physical tasks in an unstructured work environment and in awkward positions.

The tasks identified by Montobbio et al. (2020) actually map the semantic domains covered by labor-saving patents and emerging out of the probabilistic topic model: for example, tasks related to perception and manipulation, cognitive intelligence, and social intelligence, appear to be more prevalent in labor-saving patents, compared to generic robotic patents. Therefore, according to their results, these technological bottlenecks are currently under the spot of cutting-edge research efforts performed by innovative firms in their knowledge space. Similarly, Webb (2020) shows that the most recent AI driven automation wave is directed at high-skilled tasks.

In these respects, future labor-saving trends detectable from search effort seem to be directed towards the substitution of tasks belonging to a wide set of heterogeneous sectors, from logistics to health. However, as shown by Montobbio et al. (2020), top holders of labor-saving patents include Boeing, Amazon, and UPS (cf. Fig. 2).

Indeed, innovative efforts aimed at automatize processes like picking and storing hardly signal paradigmatic transformations according to which technology might be used to liberate mankind from the oppression of work, as per Keynes' prediction. Rather than the development of technologies aimed at an "Economics of 
hope" (Freeman, 1992), these efforts appear to be directed towards labor-expulsion in already very automatized processes, and wherein the substitution between human and machine would hardly result in collective gains, but rather in potential employment loss for workers employed in the logistic sector.

Clearly, labor-saving efforts in robotic patents will not necessarily map into effective labor-expulsion trends. Nonetheless, during a phase marked by the explosion of the SARS-CoV-2 pandemic, detecting the prevalence of labor-saving patents also in sectors where humans are relatively less replaceable, such as diagnosis and therapy, is not an encouraging sign. Dosi and Virgillito (2019), by identifying the current phase of capitalist development as "rentified" capitalism, call for a series of effective policy interventions, able to cope with an alternative materializing Blade Runner scenario in which technologies increase the scope for human control, while not being used to benefit society as a whole. In this respect, policies aimed at increasing workers appropriation of gains from technology, in terms of higher wage remuneration, reduction of working hours, and a more autonomous pace in organizing their work activities, are urgently needed. Additionally, redistributive policies increasing tax progressiveness and directed towards rent-erosion need to be put in place, starting with tech giants and "Big Pharma". This would apply under normal circumstances, let alone during a global pandemic. Finally, industrial policies which foster the development of sectors of activities able to absorb labor force, and at the same time to provide good jobs, might represent an alternative path to the current trend of "casualization" of work, starting with education, health, and the environment. However, all this might only come with a rebalancing of labor power.

\section{Conclusions}

The study of technology and of its unfolding upon the social fabric allows to investigate how productive forces interrelate and influence the evolution of capitalism. However, the underlying complexity of technological artifacts call for an anti-deterministic perspective and for the role exerted by other forces beyond technology in defining the evolution of the capitalist mode of production, distribution, and appropriation. Hereby, the current human-machine debate is reviewed under an anti-deterministic spotlight, eliciting limits in mainstream economic literature and giving space to alternative treatments of technology and its relationship with humans and labor demand. Next, by focusing on labor-saving heuristics embedded in patents, and therefore looking at the effective direction of search efforts in innovative activities, a map is provided of the historical evolution of labor-saving heuristics in automation, identifying phases of upsurge, saturation, and decline of the bundle of underlying technologies. Finally, by looking at the current direction of innovative efforts in labor-saving heuristics, future trends of potential labor-displacement are envisioned, particularly in the logistic sector, but also in other more human-interactive activities, such as the one involved in diagnosis and therapy. Nonetheless, by rejecting a deterministic perspective, labor-saving heuristics in the search space are not mapped one-to-one to the adoption space. It is argued that the upsurge of the pandemic and the massive switch to teleworking and online consumption is fueling new transformations in terms of patterns of delivery and distribution, and in general of commercial and social consumption activities. Policy directions and interventions remain crucial in taming and possibly pushing towards human-enhancing innovations, the alternatively disruptive nexus between humans and machines. 


\section{References}

Acemoglu, Daron and David H. Autor (2011). 'Skills, Tasks and Technologies: Implications for Employment and Earnings'. In: Handbook of Labor Economics. Ed. by David Card and Orley Ashenfelter. Vol. 4B. Elsevier. Chap. 12, pp. 1043-1171. DOI: 10.1016/S0169-7218(11)02410-5.

Acemoglu, Daron and Pascual Restrepo (2018). 'The Race between Man and Machine: Implications of Technology for Growth, Factor Shares, and Employment'. American Economic Review 108(6), pp. 1488-1542. DOI: 10.1257/aer. 20160696.

Acemoglu, Daron and Pascual Restrepo (2019). 'Automation and New Tasks: How Technology Displaces and Reinstates Labor'. Journal of Economic Perspectives 33(2), pp. 3-30. DOI: 10.1257/jep. 33.2. 3.

Acemoglu, Daron and Pascual Restrepo (2020). 'Robots and Jobs: Evidence from US Labor Markets'. Journal of Political Economy 128(6), pp. 2188-2244. DOI: 10.1086/705716.

Arntz, Melanie, Terry Gregory and Ulrich Zierahn (2016). The Risk of Automation for Jobs in OECD Countries: A Comparative Analysis. OECD Social, Employment and Migration Working Papers No. 189, OECD Publishing, Paris. DOI: 10.1787/5jlz9h56dvq7-en.

Atack, Jeremy, Robert A. Margo and Paul Rhode (2020). Mechanization Takes Command: Inanimate Power and Labor Productivity in Late Nineteenth Century American Manufacturing. NBER Working Paper No. 27436. DOI: $10.3386 /$ w27436.

Autor, David H., Frank Levy and Richard J. Murnane (2003). 'The skill content of recent technological change: An empirical exploration'. Quarterly Journal of Economics 118(4), pp. 1279-1333. DOI: 10.1162/ 003355303322552801.

Baines, Edward (1835). History of the Cotton Manufacture in Great Britain. H. Fisher, R. Fisher, and P. Jackson, London.

Biagi, Federico and Raquel Sebastian (2020). 'Technologies and 'Routinization'. In: Handbook of Labor, Human Resources and Population Economics. Ed. by Klaus F. Zimmermann. Springer. DOI: 10.1007/9783-319-57365-6_8-2.

Brynjolfsson, Erik and Andrew McAfee (2014). The Second Machine Age: Work, Progress, and Prosperity in a Time of Brilliant Technologies. W. W. Norton \& Co.

Calvino, Flavio and M. Enrica Virgillito (2018). 'The innovation employment nexus: A critical survey of theory and empirics’. Journal of Economic Surveys 32(1), pp. 83-117. DOI: 10.1111/joes. 12190.

Casilli, Antonio A. (2017). 'Digital Labor Studies Go Global: Toward a Digital Decolonial Turn'. International Journal of Communication 11, pp. 3934-3954.

Castaldi, Carolina, Roberto Fontana and Alessandro Nuvolari (2009). 'Chariots of fire: the evolution of tank technology, 1915-1945'. Journal of Evolutionary Economics 19(4), pp. 545-566. DOI: 10.1007/s00191$009-0141-0$.

Cetrulo, Armanda, Dario Guarascio and M. Enrica Virgillito (2019). Anatomy of the Italian occupational structure: concentrated power and distributed knowledge. GLO Discussion Paper 418. URL: https : //ideas . repec. org/p/zbw/glodps/418.html. 
Cetrulo, Armanda and Alessandro Nuvolari (2019). 'Industry 4.0: revolution or hype? Reassessing recent technological trends and their impact on labour'. Journal of Industrial and Business Economics 46(3), pp. 391402. DOI: $10.1007 / \mathrm{s} 40812-019-00132-y$.

Cirillo, Valeria, Matteo Rinaldini, Jacopo Staccioli and M. Enrica Virgillito (2020). 'Technology vs. workers: the case of Italy's Industry 4.0 factories'. Structural Change and Economic Dynamics. In press.

Clark, John, Christopher Freeman and Luc Soete (1981). 'Long waves and technological developments in the 20th century'. Konjunktur, Krise, Gesellschaft 25(2), pp. 132-169.

Cohen, Michael D., Roger Burkhart, Giovanni Dosi, Massimo Egidi, Luigi Marengo, Massimo Warglien and Sidney Winter (1996). 'Routines and other recurring action patterns of organizations: contemporary research issues'. Industrial and Corporate Change 5(3), pp. 653-698. DOI: 10.1093/icc/5.3.653.

Domini, Giacomo, Marco Grazzi, Daniele Moschella and Tania Treibich (2020). 'Threats and opportunities in the digital era: Automation spikes and employment dynamics'. Research Policy. In press. DOI: 10.1016/j . respol.2020.104137.

Dosi, Giovanni (1982). 'Technological paradigms and technological trajectories: A suggested interpretation of the determinants and directions of technical change'. Research Policy 11(3), pp. 147-162. DOI: 10.1016/ 0048-7333(82)90016-6.

Dosi, Giovanni and Pierre Mohnen (2019). 'Innovation and employment: an introduction'. Industrial and Corporate Change 28(1), pp. 45-49. DOI: $10.1093 /$ icc/dty064.

Dosi, Giovanni and Richard R. Nelson (2010). 'Technical Change and Industrial Dynamics as Evolutionary Processes'. In: Handbook of the Economics of Innovation. Ed. by Bronwyn H. Hall and Nathan Rosenberg. Vol. 1. North Holland. Chap. 3. DOI: 10.1016/S0169-7218(10)01003-8.

Dosi, Giovanni, Mariacristina Piva, M. Enrica Virgillito and Marco Vivarelli (2019). Embodied and Disembodied Technological Change: The Sectoral Patterns of Job-Creation and Job-Destruction. IZA Discussion Paper No. 12408. URL: https://www. iza.org/publications/dp/12408/embodied-and-disembodiedtechnological-change-the-sectoral-patterns-of-job-creation-and-job-destruction.

Dosi, Giovanni and Maria Enrica Virgillito (2019). 'Whither the evolution of the contemporary social fabric? New technologies and old socio-economic trends'. International Labour Review 158(4), pp. 593-625. DOI: $10.1111 /$ ilr. 12145 .

DuPont Chandler Jr., Alfred (1993). The Visible Hand: The Managerial Revolution in American Business. Belknap Press.

Ford, Martin (2015). The Rise of the Robots. Technology and the Threat of Mass Unemployment. Basic Books.

Freeman, Chris (2019). 'History, co-evolution and economic growth'. Industrial and Corporate Change 28(1), pp. 1-44. DOI: $10.1093 / \mathrm{icc} / \mathrm{dty} 075$.

Freeman, Christopher (1992). The economics of hope essays of technical change, economics growth an the environment. PINTER Publisher.

Freeman, Christopher, John Clark and Luc Soete (1982). Unemployment and technical innovation: a study of long waves and economic development. Burns \& Oates.

Freeman, Christopher and Luc Soete (1987). Technical change and full employment. B. Blackwell. 
Frey, Carl Benedikt and Michael A. Osborne (2017). 'The future of employment: How susceptible are jobs to computerisation?' Technological Forecasting and Social Change 114, pp. 254-280. DOI: 10.1016 / j . techfore.2016.08.019.

Graetz, Georg and Guy Michaels (2018). 'Robots at Work'. Review of Economics and Statistics 100(5), pp. 753768. DOI: 10.1162/rest_a_00754.

Huws, Ursula (2014). Labor in the Global Digital Economy: The Cybertariat Comes of Age. Monthly Review Press.

Katz, Lawrence F. and Kevin M. Murphy (1992). 'Changes in relative wages, 1963-1987: supply and demand factors'. Quarterly Journal of Economics 107(1), pp. 35-78. DOI: 10.2307/2118323.

Koch, Michael, Ilya Manuylov and Marcel Smolka (2019). Robots and firms. CESifo Working Paper No. 7608. URL: https://www. cesifo.org/en/publikationen/2019/working-paper/robots-and-firms.

Krzywdzinski, Martin (2020). Automation, Digitalization, and Changes in Occupational Structures in the Automobile Industry in Germany, the United States, and Japan: A Brief History from the Early 1990s Until 2018. (Weizenbaum Series \#10) Berlin: Weizenbaum Institute for the Networked Society. URL: https: //www. weizenbaum-institut.de/media/Publikationen/Weizenbaum_Series/Weizenbaum_Series_ 10_Krzywdzinski.pdf.

Martinelli, Arianna (2012). 'An emerging paradigm or just another trajectory? Understanding the nature of technological changes using engineering heuristics in the telecommunications switching industry'. Research Policy 41(2), pp. 414-429. DOI: 10.1016/j. respol.2011.10.012.

Montobbio, Fabio, Jacopo Staccioli, M. Enrica Virgillito and Marco Vivarelli (2020). Robots and the origin of their labour-saving impact. LEM Working Paper Series 2020/03. URL: http : / www . lem. sssup . it / WPLem/2020-03.html.

Moro, Angelo, Matteo Rinaldini, Jacopo Staccioli and M. Enrica Virgillito (2019). 'Control in the era of surveillance capitalism: an empirical investigation of Italian Industry 4.0 factories'. Journal of Industrial and Business Economics 46(3), pp. 347-360. DOI: 10.1007/s40812-019-00120-2.

National Commission on Technology, Automation, and Economic Progress (1966). Technology and the American Economy. U.S. Government Printing Office, Washington D.C.

Nedelkoska, Ljubica and Glenda Quintini (2018). Automation, skills use and training. OECD Social, Employment and Migration Working Papers, No. 202. OECD Publishing, Paris. DOI: 10.1787/2e2f4eea-en.

Nuvolari, Alessandro (2002). 'The 'machine breakers' and the industrial revolution'. Journal of European Economic History 31(2), pp. 393-426.

Pardi, Tommaso, Martin Krzywdzinski and Boy Lüthje (2020). Digital manufacturing revolutions as political projects and hypes: evidences from the auto sector. ILO Working Paper 3, April 2020. URL: https : / / labordoc.ilo.org/permalink/41ILO_INST/j3q9on/alma995073193302676.

Pfeiffer, Sabine (2018). 'The 'Future of Employment' on the Shop Floor: Why Production Jobs are Less Susceptible to Computerization than Assumed'. International journal for research in vocational education and training 5(3), pp. 208-225. DOI: 10.13152/I JRVET.5.3.4. 
Piva, Mariacristina and Marco Vivarelli (2018). 'Technological change and employment: is Europe ready for the challenge?' Eurasian Business Review 8(1), pp. 13-32. DOI: 10.1007/s40821-017-0100-x.

Rosenberg, Nathan (1976). Perspectives on Technology. 1st ed. Cambridge University Press. DOI: 10.1017/ cbo9780511561313.

Simonetti, Roberto, Karl Taylor and Marco Vivarelli (2000). 'Modelling the employment impact of innovation'. In: The Employment Impact of Innovation. Ed. by Mario Pianta and Marco Vivarelli. Routledge. Chap. 3, pp. 26-43.

Staccioli, Jacopo and M. Enrica Virgillito (2020). 'Back to the past: the historical roots of labour-saving automation'. Eurasian Business Review. In press.

Taalbi, Josef (2017). 'What drives innovation? Evidence from economic history'. Research Policy 46(8), pp. 1437-1453. DOI: 10.1016/j. respol.2017.06.007.

Thompson, Edward P. (1963). The Making of the English Working Class. Victor Gollancz, London.

Trajtenberg, Manuel (2019). 'Artificial Intelligence as the Next GPT: A Political-Economy Perspective'. In: The Economics of Artificial Intelligence: An Agenda. Ed. by Ajay Agrawal, Joshua Gans and Avi Goldfarb. University of Chicago Press.

Vivarelli, Marco (1995). The Economics of Technology and Employment: Theory and Empirical Evidence. Edward Elgar Pub.

von Tunzelmann, G. Nick (1995). 'Time-Saving Technical Change: The Cotton Industry in the English Industrial Revolution'. Explorations in Economic History 32(1), pp. 1-27. DOI: 10.1006/exeh. 1995. 1001.

Webb, Michael (2020). The Impact of Artificial Intelligence on the Labor Market. Available at SSRN. URL: https://ssrn. com/abstract=3482150.

Wired (2017). Big data meets Big Brother as China moves to rate its citizens. https: //www. wired.co. uk/ article/chinese-government-social-credit-score-privacy-invasion.

Zuboff, Shoshana (2015). 'Big other: surveillance capitalism and the prospects of an information civilization'. Journal of Information Technology 30(1), pp. 75-89. DOI: 10.1057/jit.2015. 5. 


\section{Quaderni del Dipartimento di Politica Economica}

1. Innovation, jobs, skills and tasks: a multifaceted relationship. M. Piva, M. Vivarelli, Vita e Pensiero, maggio 2018 (ISBN 978-88-343-3654-0)

2. A bridge over troubled water: Interdisciplinarity, Novelty, and Impact. M. Fontana, M. Iori, F. Montobbio, R. Sinatra, Vita e Pensiero, settembre 2018 (ISBN 978-88-343-3793-6)

3. Concordance and complementarity in IP instruments. M. Grazzi, C. Piccardo, C. Vergari, Vita e Pensiero, gennaio 2019 (ISBN 978-88-343-3879-7)

4. Sustainable finance, the good, the bad and the ugly: a critical assessment of the EU institutional framework for the green transition. L. Esposito, E.G. Gatti, G. Mastromatteo, Vita e Pensiero, febbraio 2019 (ISBN 978-88-343-3892-6)

5. Technology and employment in a vertically connected economy: a model and an empirical test. G. Dosi, M. Piva, M.E. Virgillito, M. Vivarelli, Vita e Pensiero, giugno 2019 (ISBN digital edition [PDF]: 97888-343-4008-0)

6. Testing the employment impact of automation, robots and AI: A survey and some methodological issues. L. Barbieri, C. Mussida, M. Piva, M. Vivarelli, Vita e Pensiero, settembre 2019 (ISBN digital edition [PDF]: 978-88-343-4052-3)

7. A new proposal for the construction of a multi-period/multilateral price index. C.R. Nava, A. Pesce, M.G. Zoia, Vita e Pensiero, ottobre 2019 (ISBN digital edition [PDF]: 978-88-343-4114-8)

8. Lo Stato Sociale: da "lusso" a necessità. L. Campiglio, Vita e Pensiero, febbraio 2020 (ISBN digital edition [PDF]: 978-88-343-4184-1)

9. Robots and the origin of their labour-saving impact. F. Montobbio, J. Staccioli, M.E. Virgillito, M. Vivarelli, Vita e Pensiero, marzo 2020 (ISBN digital edition [PDF]: 978-88-343-4196-4)

10. Business visits, technology transfer and productivity growth. M. Piva, M. Tani, M. Vivarelli, Vita e Pensiero, marzo 2020 (ISBN digital edition [PDF]: 978-88-343-4210-7)

11. Technology, industrial dynamics and productivity: a critical survey. M. Ugur, M. Vivarelli, Vita e Pensiero, settembre 2020 (ISBN digital edition [PDF]: 978-88-343-4406-4)

12. Back to the past: the historical roots of labour-saving automation. J. Staccioli, M.E. Virgillito, Vita e Pensiero, novembre 2020 (ISBN digital edition [PDF]: 978-88-343-4473-6)

13. The present, past, and future of labor-saving technologies. J. Staccioli, M.E. Virgillito, Vita e Pensiero, dicembre 2020 (ISBN digital edition [PDF]: 978-88-343-4479-8) 